\title{
Attentional Influences on Noxious and Innocuous Cutaneous Heat Detection in Humans and Monkeys ${ }^{1}$
}

\author{
M. CATHERINE BUSHNELL, ${ }^{2}$ GARY H. DUNCAN, ${ }^{2}$ RONALD DUBNER, ${ }^{3}$ RICHARD L. JONES, AND \\ WILLIAM MAIXNER
}

Neurobiology and Anesthesiology Branch, National Institute of Dental Research, National Institutes of I lealth, Bethesda, Maryland 20205

\begin{abstract}
This study examines whether selective attention can influence sensory-discriminative aspects of nociception in humans and monkeys trained to detect innocuous and noxious thermal stimuli. Human subjects had two contact thermodes positioned bilaterally above the upper lip. Upon trial initiation both thermodes heated to either $39^{\circ} \mathrm{C}$, an innocuous warm temperature, or $45^{\circ} \mathrm{C}$, a slightly noxious temperature. After 4 to $9 \mathrm{sec}$, the temperature of one thermode increased an additional step of $<1^{\circ} \mathrm{C}$. Subjects released a button when they detected this second temperature increase (T2). Three types of trials were presented in order to assess the effects of spatially selective attention on thermal detection. On $40 \%$ of the trials a light correctly signaled the location of the thermode on which T2 would occur. On $10 \%$ of trials a light incorrectly signaled the location of T2. No signal was presented on the remaining trials. From the $45^{\circ} \mathrm{C}$ base line, detection latencies were shortest in the correct signal condition, longest in the incorrect signal condition, and intermediate in the unsignaled condition. The percent of undetected T2s was greatest in the incorrect signal condition and least in the correct signal condition. From the $39^{\circ} \mathrm{C}$ base line, the detection latency in the incorrect signal condition was greater than in the unsignaled condition, but the latter latency was not different from the correct signal latency. In addition, the percent of undetected T2s was the same on all three types of trials.
\end{abstract}

In a similar task, two monkeys were trained to detect the onset of $\mathrm{T} 2$ from $39^{\circ} \mathrm{C}$ or $45^{\circ} \mathrm{C}$ base lines on one probe or to detect the onset of a visual cue. The effect of stimulus modality selective attention on thermal detection was assessed by signaling the relevant cue on $50 \%$ of the trials. From the $45^{\circ} \mathrm{C}$ base line, both monkeys detected more T2s and produced shorter detection latencies in the signaled

Received July 13, 1984; Revised October 15, 1984;

Accepted October 24, 1984

' We wish to thank Drs. Dan R. Kenshalo, Jr., and Richard Gracely for their helpful comments on previous drafts of the manuscript. We also are grateful to Fred Brown and Sheila Taylor for their technical assistance and to Edith Welty for preparation of the manuscript.

${ }^{2}$ Present address: Département de Stomatologie, Faculté de Médecine dentaire, Université de Montréal, Montréal, Québec, Canada H2V $3 B 5$.

${ }^{3}$ To whom correspondence should be sent, at his present address: Neurobiology and Anesthesiology Branch, National Institute of Dental Research, NIH, Building 30, Room B-20, 9000 Rockville Pike, Bethesda, MD 20205. condition than in the unsignaled condition. The one monkey tested at the $39^{\circ} \mathrm{C}$ base line had shorter detection latencies in the signaled condition, but the percent of undetected T2s was the same in both conditions.

These data suggest that attentional manipulations have greater effects on detection latencies in the noxious heat range than on detection latencies in the warming range. Since temperatures of $39^{\circ} \mathrm{C}$ and $45^{\circ} \mathrm{C}$ are largely signaled by different peripheral and central neurons, these findings suggest that nociceptive pathways are more sensitive to attentional factors than innocuous thermal pathways.

Perception of painful stimuli can be altered by behavioral factors such as attention. Anecdotal evidence such as athletes noticing painful injuries only after the completion of a game is supported by both human and animal experiments. When people are required to attend to something else while receiving a painful stimulus, they rate the pain lower (Leventhal et al., 1979; Willer et al., 1979; McCaul and Haugtvedt, 1982; Ahles et al., 1983). Conversely, patients rate postsurgical pain as more intense when they are required to attend to the pain more frequently (Levine et al., 1982). Finally, cats are less likely to react to painful stimuli when they are eating and presumably distracted than when they are not (Casey and Morrow. 1983).

The concept of attention has various meanings, and each may have different physiological correlates (Berlyne, 1969; Näätänen, 1975; Posner, 1980). Sometimes attention refers to intensive phenomena such as alertness, arousal, or vigilance. More often, attention refers to some type of selective phenomenon that influences the organism's response to various competing environmental stimuli. Selective attention can involve choosing among different modalities, such as attending to auditory stimuli over visual stimuli. Selective attention can also involve extracting a particular property from a stimulus, such as color or temperature. Finally, attention can be selective in terms of spatial location. This spatially selective attention could occur in any sensory modality, so that the organism responds to a somesthetic, visual, or auditory stimulus in one location to the exclusion of stimuli in other locations.

Independent of the type of attention involved, a shift in attention may be accompanied by an orientation of the appropriate sensory receptor to the stimulus. Sensory receptor orienting responses such as saccades, pinna orientation, or finger movements which augment tactile sensibility lead to a change in peripheral stimulation, thereby enhancing the sensory signal. However, shifts in attention that are not accompanied by a receptor orienting response can modulate the processing of sensory information within the central nervous system (Hyvärinen et al., 1980; Wurtz ct al., 1980; Bushnell et al., 1981; Hayes et al., 1981). This central modulation may also influence the perception of the stimulus. 
Pain is a multidimensional phenomenon, involving both sensorydiscriminative and affective components, each of which may have different neural substrates (Melzack and Wall, 1965; Melzack and Casey, 1968; Price and Dubner, 1977). Discriminative components of pain involve such dimensions as intensity, quality, duration, and location, while affective components involve such aspects as motivational significance and relative unpleasantness of a stimulus. Investigators have separated the sensory and affective components of perception in humans (Gracely et al., 1978). However, studies of attentional influences on pain perception have generally utilized a single measure of the pain experience that probably encompasses both sensory and affective dimensions (Craig et al., 1978; Leventhal et al., 1979; Willer et al., 1979; Thelen and Fry, 1981; McCaul and Haugtvedt, 1982; Levine et al., 1982; Ahles et al., 1983).

The present study is designed to analyze the effects of selective attention on the sensory-discriminative aspects of pain in humans and monkeys. Specifically, we investigated the effects of attention to noxious heat stimuli applied to the face on the detection of small changes in those stimuli. Ihe human experiment evaluates the effects of spatially selective attention, and the monkey experiment evaluates the effects of attention between the noxious thermal and visual modalities. In addition, we performed similar experiments using innocuous warm stimuli and compared the influence of attentional manipulations on nociceptive and nonnociceptive systems. The techniques employed are modifications of those developed by Posner $(1978,1980)$ and Posner et al. $(1978,1980)$ to study attentional influences in the visual system. Some of these data have been described previously (Bushnell et al., 1983a).

\section{Materials and Methods}

\section{Human experiments}

Five male and three female volunteer subjects between the ages of 20 and 40 performed psychophysical experiments. All were naive about the aims of the experiment but were informed about the experimental procedure. Subjects signed a consent form in which they acknowledged that the experimental procedure had been explained adequately and also that they were free to withdraw, without prejudice, from the experiment at any time.

The subjects were seated in a quiet room with a response panel in front of them. On the panel was a response button and two signal lights, shown in Figure 1. Subjects positioned two 1-cm-diameter contact thermodes above their upper lip, approximately $? \mathrm{~cm}$ apart and equidistant from the midline. Each thermode consisted of a copper heat sink containing a spiral nichrome heating element embedded in epoxy and covered by a thin copper face. A small thermistor was placed at the surface of the thermode face and sensed the temperature of the junction between the thermode and skin (see Beitel and Dubner, 1976, for details). Feedback-controlled temperature shifts were presented with a rise-time of $8 \% \mathrm{sec}$. Circulating refrigerated water returned the temperature to base line at a controlled rate of $8 \% \mathrm{sec}$. All stimulus presentations were controlled by a PDP-11 computer.

Basic task. The response button was illuminated at the beginning of each trial (Fig. 1, I-A). Subjects were instructed to press the illuminated button and keep it depressed throughout the trial. As soon as the button was pressed, the temperature of each thermode increased at $8 \% \mathrm{sec}$ from a base line of $32^{\circ} \mathrm{C}$ to a final temperature of $39^{\circ} \mathrm{C}$ or from a base line of $38^{\circ} \mathrm{C}$ to a final temperature of $45^{\circ} \mathrm{C}$ (T1 in Fig. $1,1-\mathrm{C}$ ). After a variable time (4 to $9 \mathrm{sec}$ ), the temperature of one thermode increased by a variable amount. Subjects were instructed to release the button when they detected this second temperature increase (T2 in Fig. 1, 1-C). On 50\% of trials, T2 occurred on the left thermode and, on $50 \%$ of trials, T2 occurred on the right thermode. If the subject released the button within $2 \mathrm{sec}$ of T2, a 0.5 -sec beep indicated a "correct response." If the subject continued to press the button beyond this 2 -sec interval, a buzzer sounded, indicating that the subject had failed to detect the temperature cue. This type of response was labeled a "no response." If the subject released the button before $T 2$, no auditory signal occurred, indicating an "early release." A 15-sec intertrial interval followed each correct resonse, no response, or early release.

Each subject was given two days of training using this basic task, with a $\mathrm{T} 1$ of $39^{\circ} \mathrm{C}$ on one day and a $\mathrm{T} 1$ of $45^{\circ} \mathrm{C}$ on the other day. During each training day of 160 trials, various T2 steps were presented, ranging from $1.0^{\circ} \mathrm{C}$ to $0.2^{\circ} \mathrm{C}$, using a descending method of limits. The T2 value detected on approximately $75 \%$ of trials was calculated for each subject at $39^{\circ} \mathrm{C}$ and $45^{\circ} \mathrm{C}$ base lines and was used for subsequent testing sessions (see Table 1). These values were well above threshold (chance was less than $33 \%$ correct in this task) but still difficult enough to produce some detection failures (ro responses)

Experimental paradigm. Subjects performed the basic task for two days and then performed a modified task that assessed the effects of spatially selective attention on detection of thermal stimulus changes. Three types of trials were presented. Fifty percent of the trials were identical to those used on the training days (Fig. $1, l$ ), except that $\mathrm{T} 2$ was always the value determined from the training sessions. These were designated "neutral" trials. On $40 \%$ of the trials a signal light was illuminated throughout the trial and correctly signaled the corresponding lncation of the thermode on which T2 would occur (Fig. 1, II). For example, if the left signal was illuminated, T2 would occur on the left thermode. These were designated "correct signal" trials. Finally, on $10 \%$ of trials a signal light illuminated throughout the trial incorrectly signaled the location of T2 (Fig. 1, III). That is, if the right signal was illuminated, T2 would occur on the left thermode. These were designated "incorrect signal" trials.

Subjects received two 160 -trial sessions with a $T 1$ of $39^{\circ} \mathrm{C}$ and two 160 trial sessions with a $\mathrm{T} 1$ of $45^{\circ} \mathrm{C}$. Half the subjects received $39^{\circ} \mathrm{C}$ sessions first, and half received $45^{\circ} \mathrm{C}$ sessions first. I he sequence of trial types within a session was randomized. However, the distribution of random foreperiod lengths, the time between the onset of $\mathrm{T} 1$ and $\mathrm{T} 2$, was balanced among trial types.

Instructions to subjects. Subjects were instructed to use the signal lights by attending to the left thermode when the left signal light was illuminated and to the right thermode when the right signal light was illuminated. Additionally, subjects were informed that, usually, the signal light would correctly indicate the location of T2 (correct signal trials) and thus facilitate their performance, but occasionally the signal light would indicate the wrong thermode (incorrect signal trials). Subjects were asked always to attend to the signaled thermode, despite the occasional incorrect signals.

Some deception was used to keep the subjects naive as to the goals of the experiment. The true dependent variables studied were detection latency and percent of cues not detected (no respnses). Subjects were told that various $T 2$ values would be presented, although this was false after the initial training sessions. Further, they were incorrectly told that the experiment was designed to determine the minimum detectable temperature change at noxious and innocuous thermal base lines and the effects of attention on those detection thresholds.

\section{Monkey experiments}

Two adolescent male rhesus monkeys (Macaca mulatta) performed psychophysical experiments similar to those of the human subjects. During the experiment the monkey sat in a primate chair, with his muzzle positioned in a molded soft-acrylic arch. A response panel was attached to the front of the chair, and the thermal stimuli were delivered by a contact thermode applicd to the hairy skin above the upper lip on one side only. The monkeys remained in the chair only during the actual training and testing periods, and they rested unrestrained in the home cage at all other times. Fruit punch was used as a reinforcer. Food and water were given immediately after a testing session. The monkeys' weights were monitored daily and maintained at a constant level.

The monkeys' tasks were similar to those of the humans, with one major exception. While the humans were required to attend to a spatial location of one of two thermal stimuli, the monkeys were required to attend to one of two stimulus modalities, i.e., thermal or visual. This stimulus modality attention task was chosen because previous studies in our laboratory indicated that monkeys did not always use the visual signal reliably in the spatial attention task performed by the humans. While human subjects could be instructed to attend to particular cues, the only instructions to the monkeys were reward contingencies. Since the cost of failing to use the visual signal was minimal, a more salient experimental manipulation was required. The monkeys' task also allowed us to determine if attention between modalities affects stimulus detection in a manner similar to spatial attention within a modality. Pilot data were collected from one human subject in the monkey paradigm. This subject produced data comparable to those of the monkeys.

Unsignaled thermal task. The monkeys were first trained to perform the same basic thermal task as the humans (Fig. 1, I and Fig. 2, I). The monkey pressed the illuminated response button at the beginning of a trial (Fig. 2, 1A). The thermode temperature then increased from a base line of $32^{\circ} \mathrm{C}$ to $39^{\circ} \mathrm{C}(\mathrm{T} 1)$ or from $38^{\circ} \mathrm{C}$ to $45^{\circ} \mathrm{C}(\mathrm{T} 1)$, remained at the elevated level for 3 to $10 \mathrm{sec}$, and then increased an additional small step (T2) that was usually less than $1{ }^{\circ} \mathrm{C}$. When the monkeys released the button within $2 \mathrm{sec}$ of $\mathrm{T} 2$, a beep sounded, indicating a "correct response," $0.5 \mathrm{ml}$ fruit juice reward was 


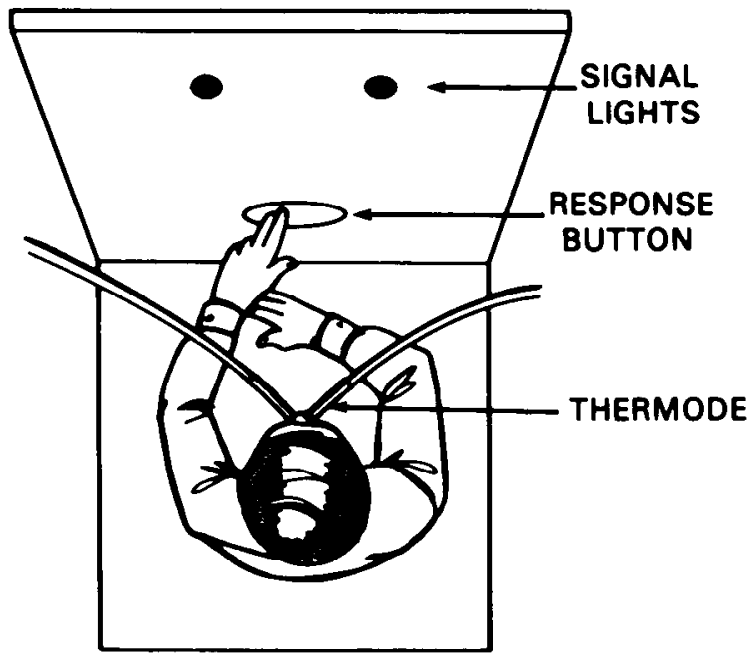

\section{NEUTRAL}

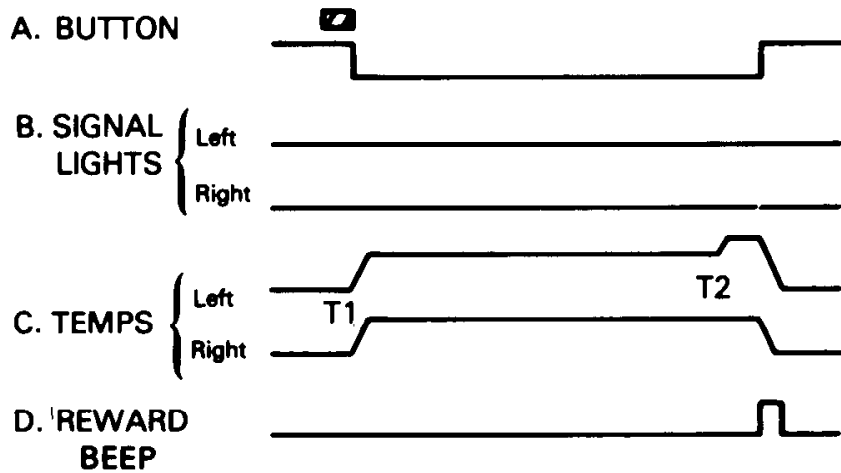

\section{CORRECT SIGNAL}

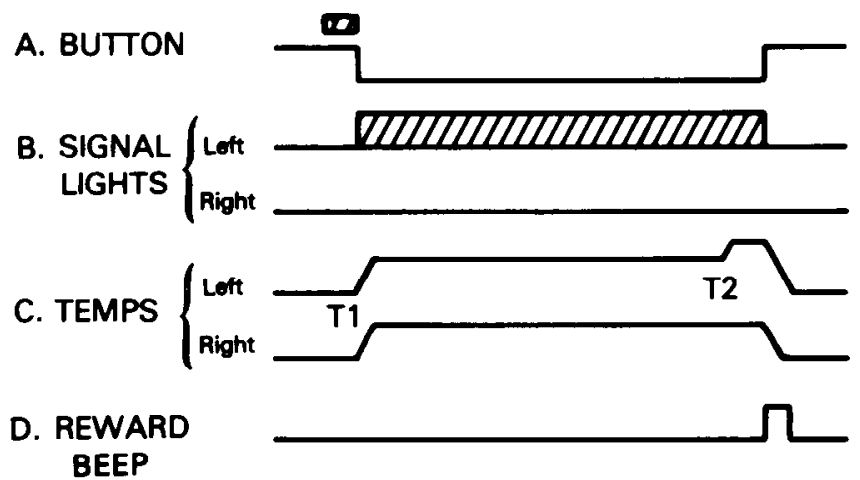

\section{INCORRECT SIGNAL}

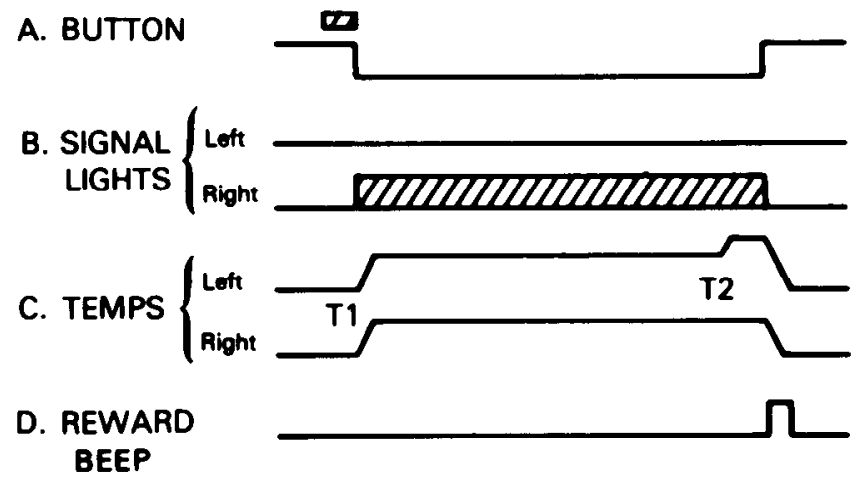

Figure 1. The human attention task. The drawing shows a subject seated in front of the response panel containing a stimulus/response button and two signal lights. Two thermodes were positioned bilalerally above the upper lip. Parl / shows the neulral lask, in which the subject initiated the trial by pressing the response button when it was illuminated $(I-A)$. Neither signal light was illuminated $(I-B)$, but both thermodes heated simultaneously to $39^{\circ} \mathrm{C}$ in some sessions and $45^{\circ} \mathrm{C}$ in other sessions $(T 1$ in $1-C)$. After a variable time, one thermode heated an additional step of less than $1^{\circ} \mathrm{C}(T 2$ in $1-C)$. Subjects received a reward beep (I-D) if they released the button within $2 \mathrm{sec}$ of T2. Parts $/ /$ and $/ / I$ show the correct signal task and incorrect signal task, respectively. These resembled the neutral task, except that a signal light was illuminated when the subject initiated a trial by pressing the button and remained illuminated until he released the button (II-B and $/ / I-B)$. In the correct signal condition, the signal light corresponded to the thermode side on which T2 would occur (II-B and $I I-C)$. In the incorrect signal condition, the signal light did not correspond to the side of T2 (III-B and III-C).

delivered (Fig. 2, I-E), and the thermode temperature returned to base line. As with the humans, no auditory cue followed an "early release," and a buzzer followed a "no response." Each monkey was trained on the thermal task until he performed at greater than $90 \%$ accuracy.

Unsignaled visual task. The monkeys were also trained to perform a visual detection task (Fig. 2,III). As in the thermal task, the monkeys pressed the illuminated response button; the thermode heated from $32^{\circ} \mathrm{C}$ or $38^{\circ} \mathrm{C}$ to $39^{\circ} \mathrm{C}$ or $45^{\circ} \mathrm{C}$, respectively, and remained at the elevated level for 3 to 10 sec. However, in the visual task, a cue light was illuminated at this time (Fig. $2, I I I-D)$. The monkeys were rewarded for releasing the response button within 2 sec of the cue light onset. The temperature remained at T1 until the monkeys released the response button or until $2 \mathrm{sec}$ after the cue light onset. Early releases and no responses were treated as in the thermal task. The monkeys readily learned to perform this task with greater than $90 \%$ accuracy.

Signaled thermal task. On some thermal irials, a red signal light was illuminated throughout the trial, correctly indicating that the reinforced cue was to be a temperature shift (T2) (Fig. 2, $/ 1-B$ and $/ I-C$ ). No visual cue occurred on these trials.

Signaled visual task. On some visual trials, a blue signal light was illuminated throughout the trial, correctly indicating that the reinforced cue was to be the visual cue (Fig. 2, $I$-B). On these trials, T2 occurred, but the monkeys were not rewarded for responding to its occurrence (Fig. 2, $N-C$ ). Instead, they were required to continue pressing the button until the onset of the visual cue (Fig. 2, $N-D$ )
Experimental paradigm. When the monkeys could perform all trial types, T2 values were chosen that they could detect approximately $75 \%$ of the time (see Table II). The four trial types were randomly mixed, with each occurring on $25 \%$ of the 160 trials in each session. Foreperiod lengths of 3 to $10 \mathrm{sec}$ were matched among trial types.

Each monkey was tested for 13 sessions using a $\mathrm{T} 1$ of $45^{\circ} \mathrm{C}$. In addition, one monkey was tested for 13 sessions using a $\mathrm{T} 1$ of $39^{\circ} \mathrm{C}$. Both monkeys were subsequently used for physiological experiments in order to examine possible neural substrates of selective attention (to be published separately).

\section{Datá analysis}

Mean and median latencies, percentage of no responses, and percentage of early releases were calculated for each type of trial for each human subject. Medians were calculated in addition to means because of the skewed nature of latency distributions. Furthermore, the use of median values allowed us to calculate latencies from both correct responses and no responses. Mean latencies were calculated from correct responses only. Parametric and nonparametric statistical analyses were performed across subjects.

Similar analyses were performed for the monkeys, except that each monkey's data were analyzed separately. For each monkey, statistical analyses were performed across the 13 experimental sessions. Latencies, no responses, and early releases are presented only for signaled and unsignaled thermal trials. Visual trials were included solely to manipulate 
TABLE I

T2 detection levels in human subjects

\begin{tabular}{|c|c|c|c|c|c|c|}
\hline \multirow[b]{2}{*}{ Subject } & \multicolumn{3}{|c|}{$39^{\circ} \mathrm{C}$} & \multicolumn{3}{|c|}{$45^{\circ} \mathrm{C}$} \\
\hline & T2 $(\Delta)$ & $\begin{array}{l}\text { Percentage } \\
\text { Correct }^{\mathrm{a}}\end{array}$ & $\begin{array}{c}\text { Latis-Lat }_{\mathrm{cs}}{ }^{b} \\
\text { (msec) }\end{array}$ & $\mathrm{T} 2(\Delta)$ & $\begin{array}{l}\text { Percentage } \\
\text { Correct }^{\star}\end{array}$ & $\begin{array}{c}\text { Lat }_{\text {is }}-\text { Lat }_{\mathrm{cs}} \\
(\mathrm{msec})\end{array}$ \\
\hline $\mathrm{JC}$ & 0.30 & 68 & -60 & 0.30 & 77 & +180 \\
\hline $\mathrm{RB}$ & 0.25 & 71 & +110 & 0.25 & 69 & +130 \\
\hline $\mathrm{MH}^{c}$ & 1.05 & 71 & +160 & 0.90 & 84 & +50 \\
\hline $\mathrm{JO}$ & 0.45 & 76 & +150 & 0.30 & 92 & +80 \\
\hline $\mathrm{FB}$ & 0.50 & 80 & +60 & 0.35 & 81 & +230 \\
\hline $\mathrm{KC}$ & 0.50 & 81 & +170 & 0.40 & 77 & +60 \\
\hline GD & 0.40 & 86 & +90 & 0.35 & 81 & +200 \\
\hline VM & 0.55 & 90 & +160 & 0.45 & 86 & +120 \\
\hline \multirow[t]{3}{*}{$\bar{x}$} & 0.50 & 78 & +105 & 0.41 & 81 & +131 \\
\hline & & \multirow{2}{*}{\multicolumn{2}{|c|}{$\begin{array}{l}r=0.41 \\
r^{2}=0.17\end{array}$}} & & \multicolumn{2}{|c|}{$r=-0.24$} \\
\hline & & & & & \multicolumn{2}{|c|}{$r^{2}=0.06$} \\
\hline
\end{tabular}

${ }^{2}$ Based on mean percentage correct for each subject.

${ }^{b}$ is, incorrect signal condition; cs, correct signal condition; Lat, mean latency.

${ }^{c}$ Thermode below lower lip, because of mustache.

attention and were not analyzed, since there was no control or monitoring of eye position.

In some sessions, electromyogram (EMG) activity was recorded from the obicularis oris muscles of the two monkeys to analyze possible differences among trial types in facial movement around the thermode during or following thermal stimulation. Such activity was monitored every $8 \mathrm{msec}$ and stored in a PDP $/ 11$ computer for graphic display.

\section{Results}

\section{Human experiments}

Response latencies. In the noxious $45^{\circ} \mathrm{C}$ base line condition, all eight subjects produced the shortest response latencies on the correctly signaled trials and the longest response latencies on the incorrectly signaled trials (see Table I). Figure 3 (solid line) shows that the mean response latency of the eight subjects is shorter during the correct signal condition $(0.88 \mathrm{scc})$ than during the neutral condition $(0.93 \mathrm{sec}$ ) (paired $t$ test, $p<0.01$ ) and longer during the incorrect signal condition $(1.02 \mathrm{sec})$ than during the neutral condition (paired $t$ test, $p<0.01$ ). The median latencies of $0.88 \mathrm{sec}$ for the correct signal condition, $0.90 \mathrm{sec}$ for the neutral condition and 1.14 sec for the incorrect signal condition were also significantly different (Wilcoxon signed rank test, $p<0.05$ ).

In the innocuous $39^{\circ} \mathrm{C}$ base line condition, seven of eight subjects produced the longest mean latencies during the incorrect signal condition. Figure 3 (dashed line) shows that the mean latency of all subjects in the incorrect signal condition $(1.10 \mathrm{sec})$ is significantly different from the neutral condition $(1.01 \mathrm{sec})$ (paired $t$ test, $p<$ $0.01)$. The mean correct signal latency for all subjects $(1.00 \mathrm{sec})$ was not significantly different from that of the neutral condition. The median latencies of 0.99 for the correct signal condition, 1.00 for the neutral condition, and 1.14 for the incorrect signal condition were not significantly different.

No responses. When the base line was $45^{\circ} \mathrm{C}$, seven of eight subjects had more "no responses" in the incorrect signal condition than in the neutral condition and fewer "no responses" in the correct signal condition than in the neutral condition. The solid line in Figure 4 shows that the mean percentage of "no responses" was greater in the incorrect condition (25.8\%) than the neutral condition $(14.4 \%)$ (paired $t$-test, $p<0.01$ ) and less in the correct condition $(11.9 \%$ ) than in the neutral condition (paired $t$-test, $p<0.05$ ). The median percentage of "no response" also was significantly greater in the incorrect signal condition $(23.5 \%)$ than in the neutral condition $(15.0 \%)$ and less in the correct signal condition $(12.9 \%)$ than in the neutral condition (Wilcoxon signed rank test, $p<0.05$ ). However, when the base line was $39^{\circ} \mathrm{C}$, only four of eight subjects showed

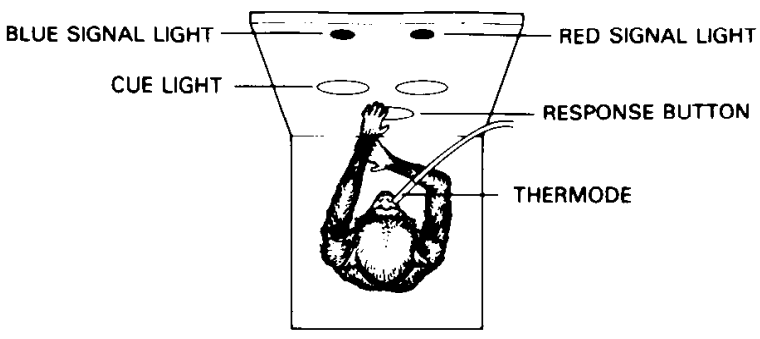

I. UNSIGNALED THERMAL

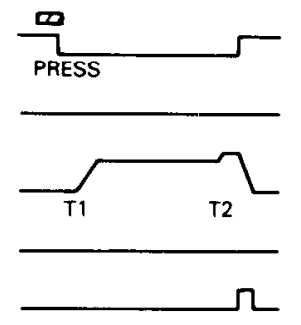

(A) BUTTON

(B) SIGNAL LIGHT

(C) TEMPERATURE

(D) CUE LIGHT

(E) REWARD

\section{SIGNALED THERMAL}
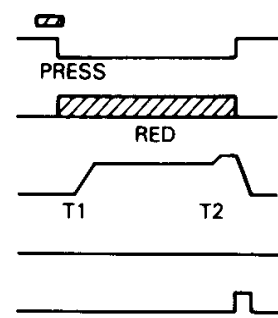

III. UNSIGNALED VISUAL

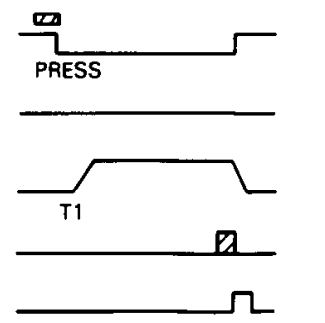

(A) BUTTON

(B) SIGNAL LIGHT

(C) TEMPERATURE

(D) CUE LIGHT

(E) REWARD
IV. SIGNALED VISUAL

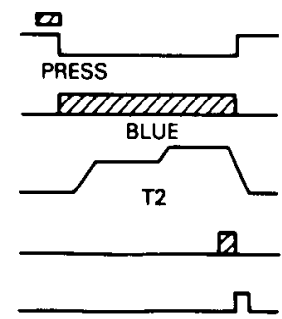

Figure 2. The monkey attention task. The drawing shows a monkey seated in front of a stimulus/response panel containing a response button, cue light, and two signal lights. One thermode was positioned on the monkey's face above his upper lip. In all conditions, the monkey initiated a trial by pressing the response button when it was illuminated $(1-A,\|-A\| 1 \mid$,$-A ,$ and $I V-A)$, and the thermode heated to $39^{\circ} \mathrm{C}$ or $45^{\circ} \mathrm{C}(T 1$ in $I-C, \| I-C, I I-C$, and $(V-C)$. On half the trials (unsignaled thermal and unsignaled visual), neither signal light was illuminated. On unsignaled thermal trials, after a variable time the thermode heated an additional step of less than $1^{\circ} \mathrm{C}(T 2$ in $1-C)$. The monkey received a juice reward for releasing the button within 2 sec of T2 $(I-A$ and $I-E)$. On unsignaled visual trials, after a variable time the cue light was illuminated $(I I I-D)$ and the monkey received a juice reward for releasing the button within $2 \mathrm{sec}$ of the cue light onset (III-A and III-E). On the other half of the trials, either the blue or red signal light was illuminated throughout the trial. During the signaled thermal trials, the red light was illuminated $(I-B)$. On these trials, T2 was the cue to be detected to obtain a reward $(I I-C)$. During the signaled visual trials, the blue light was illuminated $(I V-B)$. On these trials, T2 accurred $(I V-C)$, but the monkey was required to continue pressing the button until the cue light was illuminated $(I V-D)$. The monkey received a juice reward for releasing the button within $2 \mathrm{sec}$ of the cue light onsct ( $V A$ and $N E$ ).

more "no responses" in the incorrect signal condition than in the neutral condition. Only three subjects showed fewer "no responses" in the correct signal condition than in the neutral condition. The mean percentage of no responses for the correct signal condition $(13.9 \%)$, the neutral condition $(15.8 \%)$, and the incorrect signal condition (19.2\%) were not significantly different from each other (Fig. 4, dashed line). Correspondingly, the median percentage of no response for the correct $(16.4 \%)$, neutral $(16.0 \%)$, and incorrect $(17.7 \%)$ signal conditions were not significantly different.

Early releases. The decreased detection latencies and reduced percentage of "no responses" in the correct signal condition could reflect changes in discriminative ability or changes in the subjects' criterion for reporting a signal. Subjects that shifted their criterion in 
TABLE ॥

T2 detection levels in monkeys

\begin{tabular}{|c|c|c|c|c|c|c|c|c|c|}
\hline \multirow[b]{2}{*}{ Session } & \multicolumn{3}{|c|}{ Monkey $\mathrm{H} 39^{\circ} \mathrm{C}$} & \multicolumn{3}{|c|}{ Monkey $\mathrm{H} 45^{\circ} \mathrm{C}$} & \multicolumn{3}{|c|}{ Monkey $\mathrm{A} 45^{\circ} \mathrm{C}$} \\
\hline & $\mathrm{T} 2(\Delta)$ & $\% \mathrm{C}$ & $\begin{array}{c}\text { Lat }_{\text {us }} \text { Lat }_{c s}{ }^{a} \\
(m s e c)\end{array}$ & $\mathrm{T} 2(\Delta)$ & $\% \mathrm{C}$ & $\begin{array}{c}\text { Lat }_{\text {su }}-\text { Lat }_{\text {cs }} \\
(\mathrm{msec})\end{array}$ & $\mathrm{T} 2(\Delta)$ & $\% \mathrm{C}$ & $\begin{array}{c}\text { Lat }_{\text {su }}-\text { Lat }_{c s} \\
\text { (msec) }\end{array}$ \\
\hline 1 & 3.00 & 94 & +100 & 0.80 & 78 & +70 & 1.00 & 91 & +50 \\
\hline 2 & 3.00 & 71 & & 0.55 & 88 & & 1.00 & 81 & -20 \\
\hline 3 & 2.00 & 75 & $T$ & 0.45 & 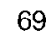 & + & 0 & & +60 \\
\hline 4 & 2.50 & 69 & +220 & 0.50 & 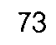 & & 0 & & +70 \\
\hline 5 & 3.00 & 70 & & 0.75 & 88 & & & 10 & +50 \\
\hline 6 & 3.00 & 68 & +90 & 0.60 & 66 & +50 & 1.00 & 82 & +100 \\
\hline 7 & 2.50 & 80 & +80 & 1.00 & 88 & -70 & 1.00 & 82 & +70 \\
\hline 8 & 3.00 & 55 & +120 & 0.60 & 90 & +40 & 1.00 & 56 & -20 \\
\hline 9 & 3.00 & 58 & +30 & 0.60 & 53 & +1 & 1.00 & 86 & +30 \\
\hline 10 & 3.0 & 57 & & 0.60 & 92 & -1 & ) & 86 & +60 \\
\hline 11 & 2.50 & 70 & -30 & 0.60 & 63 & +130 & 1.00 & 78 & +40 \\
\hline 12 & 3.00 & 67 & -100 & 0.50 & 70 & +60 & 1.00 & 79 & +20 \\
\hline 13 & 3.00 & 72 & -40 & 0.60 & 63 & +190 & 1.00 & 88 & +120 \\
\hline $\bar{x}$ & 2.81 & & $\begin{aligned} & +52 \\
= & 0.04 \\
= & 0.001\end{aligned}$ & 0.63 & & $\begin{array}{r}+62 \\
=-0.72 \\
=\quad 0.52\end{array}$ & 1.00 & & $\begin{aligned} & +48 \\
= & 0.40 \\
= & 0.16\end{aligned}$ \\
\hline
\end{tabular}

a us, unsignaled condition; cs, correct signal conditions; \%C, mean percent correct; Lat, mean latency.

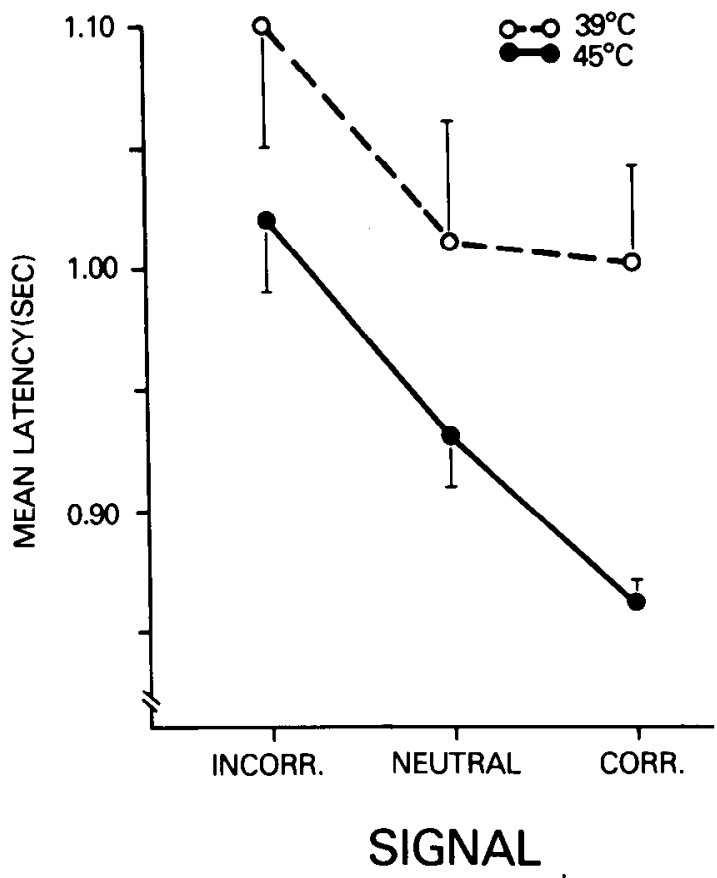

Figure 3. Mean response latencies (sec) of the eight human subjects during the incorrect signal, neutral, and correct signal conditions. The solid line represents performance at $45^{\circ} \mathrm{C}$, and the dashed line represents performance at $39^{\circ} \mathrm{C}$. Error bars show the standard error of the mean (SE). All latency values include the rise time of the thermode.

the presence of a signal in such a way that they were more likely to respond to a small change in sensation would have more "early releases" in the present paradigm. Although all subjects produced some early releases in both signaled and unsignaled conditions, there were no differences in the mean (Fig. 5) and median percentage of early releases between signaled and unsignaled conditions at base temperatures of $39^{\circ} \mathrm{C}$ or $45^{\circ} \mathrm{C}$, thus suggesting that the subjects' criterion remained the same.

Relation between task difficulty and latency differences. The values of $\mathrm{T} 2$ were chosen individually for each subject and base temperature, depending on the subject's performance during the

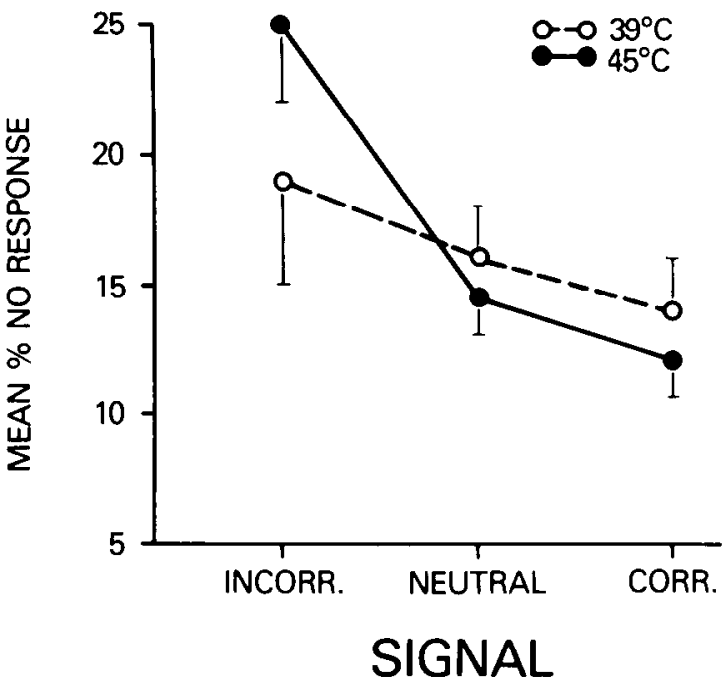

Figure 4. Mean percentage of trials in which the subject did not respond to T2 within $2 \mathrm{sec}$ (i.e., no responses), for the eight human subjects during the incorrect, neutral, and correct signal conditions. Error bars represent SE. The solid line shows the $45^{\circ} \mathrm{C}$ trials, and the dashed line shows the $39^{\circ} \mathrm{C}$ trials.

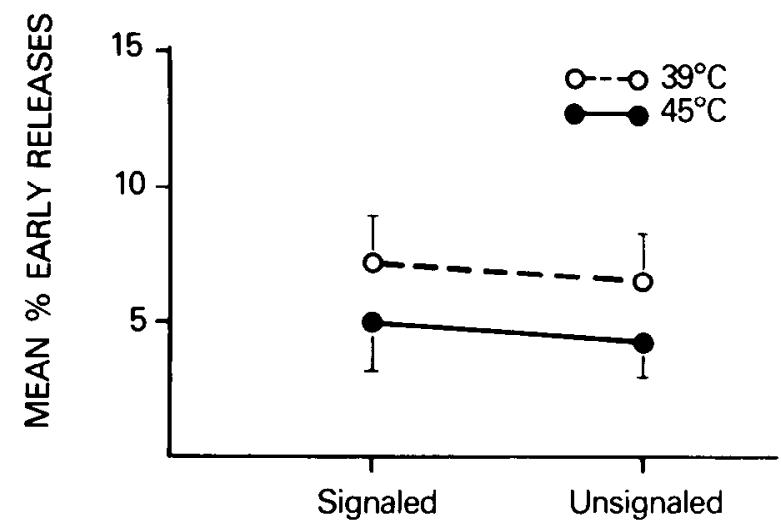

Figure 5. Mean percentage of trials in which the subject responded before $\mathrm{T} 2$ (i.e., early releases) for the eight human subjects during the signaled and unsignaled conditions. The correct and incorrect conditions are analyzed together, since these conditions are the same until the occurrence of T2. Error bars represent SE. The solid line depicts $45^{\circ} \mathrm{C}$ trials, and the dashed line depicts $39^{\circ} \mathrm{C}$ trials.

initial day of threshold determination (see "Materials and Methods") Table I shows that values were chosen which subjects detected on approximately 70 to $90 \%$ of the trials and that half of the subjects performed slightly better at the $45^{\circ} \mathrm{C}$ base temperature and half performed slightly better at the $39^{\circ} \mathrm{C}$ base temperature with the chosen T2 values. Thus, the differences in response latencies between the correct signal trials and the incorrect signal trials were not systematically related to task difficulty. Table I also shows that when the percentage of correct responses was compared with latency differences, the correlation coefficient was 0.41 at the $39^{\circ} \mathrm{C}$ base and -0.24 at the $45^{\circ} \mathrm{C}$ base, confirming the lack of relationship between response latencies and task difficulty.

\section{Monkey experiments}

$45^{\circ} \mathrm{C}$ detections. Figure 6 shows that, at the $45^{\circ} \mathrm{C}$ base temperature, both monkeys responded with shorter mean latencies on signaled than on unsignaled thermal trials (paired $t$ test, $p<0.02$ ). The mean difference between the latencies associated with the signaled and unsignaled thermal conditions was $50 \mathrm{msec}$ for monkey $A$ and 60 msec for monkey $\mathrm{H}$. At $45^{\circ} \mathrm{C}$, the median response 

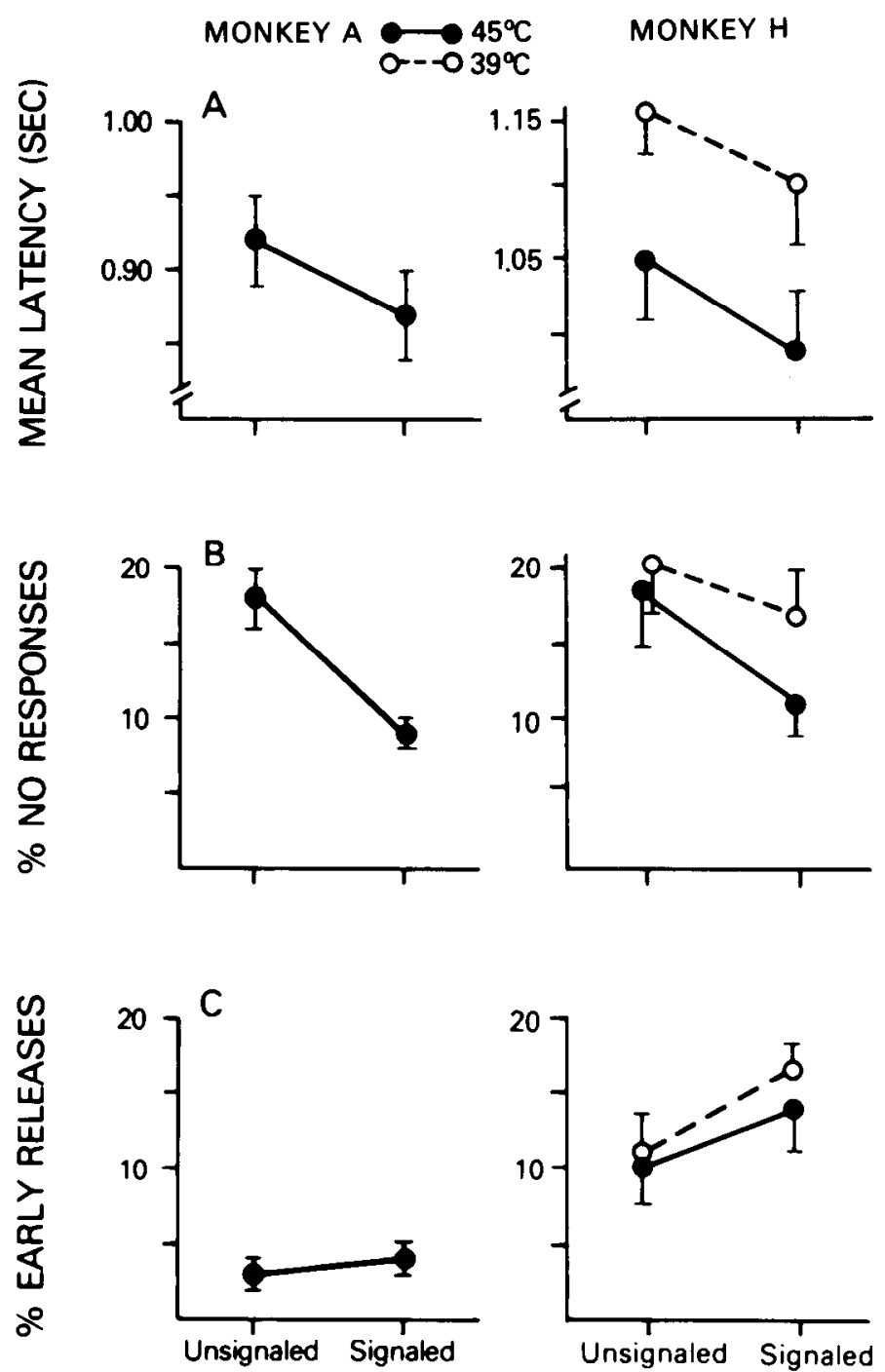

Figure 6. Mean response latency $(A)$, mean percent no responses $(B)$, and mean percent early releases $(C)$ for each monkey during the unsignaled and signaled thermal conditions. The performance of monkey $A$ was averaged across 13 sessions at a $\mathrm{T} 1$ of $45^{\circ} \mathrm{C}$, and the performance of monkey $\mathrm{H}$ was averaged across 13 sessions at a $T 1$ of $45^{\circ} \mathrm{C}$ (solid lines) and 13 sessions at a $\mathrm{T} 1$ of $39^{\circ} \mathrm{C}$ (dashed lines). Error bars show the SE.

latencies for both monkeys were significantly different in the signaled and unsignaled conditions (Wilcoxon signed rank test, $p<0.01$ )

Figure 6 shows that, for both monkeys, the mean percentage of "no responses" across sessions was smaller on signaled than on unsignaled thermal trials at a $45^{\circ} \mathrm{C}$ base temperature (paired $t$ tests, $p<0.02$ ). Similarly, for both monkeys, the median percentage of "no responses" for signaled trials was significantly less than for unsignaled trials (Wilcoxon signed rank test, $p<0.05$ ). However, at $45^{\circ} \mathrm{C}$, neither monkey produced significantly more early releases on signaled than on unsignaled trials (Fig. 6).

$39^{\circ} \mathrm{C}$ detections. Monkey $\mathrm{H}$ also performed detections from a base line temperature of $39^{\circ} \mathrm{C}$. The mean latency for signaled thermal trials was significantly different from the mean latency for unsignaled thermal trials (paired $t$ test, $p<0.05$ ). Median latencies on signaled and unsignaled trials were also different (Wilcoxon signed rank test, $p<0.01$ ). However, the mean and median percentages of "no responses" were not significantly different between the signaled and unsignaled conditions. Furthermore, the monkey appeared to shift his criterion for responding, as there were significantly more early releases on the signaled thermal trials than on the unsignaled thermal trials (paired $t$ test, $p<0.05$ ).
Task difficulty and latency differences. Values of T2 were chosen so that the monkeys averaged 70 to $80 \%$ correct responses (Table II). T2 values were sometimes changed from session to session as the monkey's discriminative ability changed. Table II shows that there was no systematic relation between task difficulty, as represented by overall percentage of correct responses, and the differences in latency between the signaled and unsignaled thermal conditions. Monkey $\mathrm{H}$ showed the largest correlation between task difficulty and latency differences at the $45^{\circ} \mathrm{C}$ base line. This correlation of -0.72 shows that there was some tendency toward larger latency differences for more difficult detections. Nevertheless, the same monkey showed no such correlation at the $39^{\circ} \mathrm{C}$ base temperature.

$E M G$ analysis. The possible confounding influence of overt sen sory receptor orienting to the thermode in the signaled thermal conditions was assessed by placing electrodes in the obicularis oris muscle of the monkey's upper lip and recording EMG activity during some experimental sessions. Figure 7 shows a representative example of average EMG activity during signaled and unsignaled thermal trials before and after T2 for monkey A. There were no systematic differences between the EMG activity in the two conditions, suggesting that the monkey was not orienting differentially to the stimulus. The response latencies were shorter on signaled trials (R1) than unsignaled trials (R2), so that the beginning of the lip movement associated with the receipt of reward was earlier on signaled trials. Nevertheless, the lip movements are not different before $\mathrm{T} 2$ and for at least $800 \mathrm{msec}$ after T2.

\section{Discussion}

In this study, the concept of attention refers to a selective phenomenon that influences an animal's response to various competing environmental stimuli. We examined the effect of selective attention on behavioral responses to spatially separate thermal stimuli and to competing thermal and visual stimuli. Attentional manipulations influenced both the detectability of intensity changes in the noxious heat range and the latency of correct detections. Within-modality attentional shifts in humans and between-modality attentional shifts in monkeys produced similar behavioral effects. Both humans and

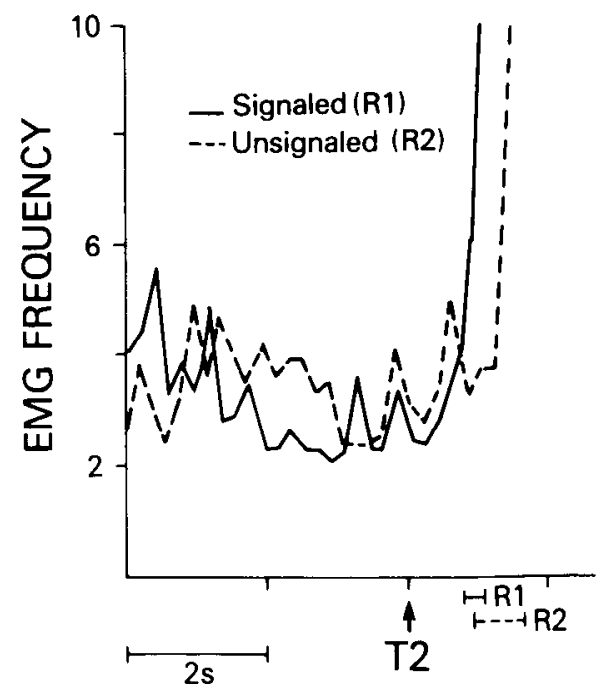

Figure 7. Sample EMG activity of the obicularis oris muscle of the upper lip averaged across one session for monkey $A$. Each trial is synchronized relative to T2. The solid line shows the signaled thermal trials, and $R 1$ (shown below the abscissa) shows the range of response latencies for these trials. The dashed line shows the unsignaled thermal trials, and $R 2$ shows the associated range of response latencies. EMG activity during drinking reached 50 to 60 units (not shown), so values of 2 to 6 units preceding T2 are very small, signifying virtually no movement. EMG activity remained low for at least $800 \mathrm{msec}$ after T2. When the monkey responded (R1 or R2), he received a juice reward and began moving his lips. 
monkeys responded approximately $50 \mathrm{msec}$ faster to temperature increases from $45^{\circ} \mathrm{C}$ when the location or modality was correctly signaled than when no signal was provided. Additionally, both humans and monkeys successfully detected more temperature changes in the correct signaled condition than in the unsignaled condition. The humans were required to focus attention on a spatial location, and the monkeys were required to focus attention on a stimulus modality. Also, in a pilot study, one human subject pertormed the intermodality task of the monkeys, with comparable results. Thus, both spatially selective and modality-selective attention appear to affect the detectability of changes in the sensory-discriminative dimension of pain perception.

In contrast to the effects of attention on noxious stimulus detection, the present data show that our attentional manipulations produced a much smaller effect on detection latency or accuracy to innocuous warm stimuli. The response latencies of humans were significantly longer during the incorrect signaled condition than the unsignaled condition, but the correct signaled condition was not different from the unsignaled condition. The one monkey lested at $39^{\circ} \mathrm{C}$ showed a $50-\mathrm{msec}$ difference between the correct signaled condition and the unsignaled condition, but he also produced more early releases during the signaled condition, suggesting that the shorter response latencies could result from a shift in response criterion. Neither humans nor monkeys showed differences in the percentage of innocuous temperature changes not detected in the signaled and unsignaled conditions.

Several observations suggest that the differential effects of attention at $45^{\circ} \mathrm{C}$ and $39^{\circ} \mathrm{C}$ are related to the temperature tested and not to other factors. First, the experimental procedures were identical at the two temperatures. Second, the differences are not a function of stimulus order, as half the subjects were tested first at $45^{\circ} \mathrm{C}$ and half were tested first at $39^{\circ} \mathrm{C}$. Finally, differences in task difficulty cannot account for the results. Half of the subjects performed slightly better at $45^{\circ} \mathrm{C}$ and half performed slightly better at $39^{\circ} \mathrm{C}$. Furthermore, there was no significant correlation between percentage of correct responses and task difficulty at either $39^{\circ} \mathrm{C}$ or $45^{\circ} \mathrm{C}$.

Nociceptive and innocuous thermal pathways. The differential effects of attention on thermal detection at $45^{\circ} \mathrm{C}$ and $39^{\circ} \mathrm{C}$ may well result from differential modulation along thermal nociceptive and nonnociceptive pathways. The largest group of primary afferent fibers innervating primate face that respond to $39^{\circ} \mathrm{C}$ stimuli are warm fibers, which begin responding to constant skin temperatures of about $30^{\circ} \mathrm{C}$ and usually show monotonic increases in firing rates with increases in skin temperature up to $40^{\circ}-43^{\circ} \mathrm{C}$ (Sumino et al., 1973; Dubner et al., 1977; Sumino and Dubner, 1981). The A-delta heat nociceptive (AHN) afferents and C-polymodal nociceptive (CPN) primary afferents innervating the primate face are maximally sensitive to temperatures in the $45^{\circ}-51^{\circ} \mathrm{C}$ range (Beitel et al, 1976; Dubner and $\mathrm{Hu}, 1977$; Dubner et al., 1977). Thus, temperatures of $39^{\circ} \mathrm{C}$ and $45^{\circ} \mathrm{C}$ are largely signaled by different groups of primary afferent fibers. Further, primate second-order trigeminothalamic neurons that respond to noxious thermal stimuli almost never have thresholds as low as $39^{\circ} \mathrm{C}$ (Poulos and Molt, 1976; Price et al., 1976; Hoffman et al., 1981; Bushnell et al., 1984). Thus, the different afferent pathways for $39^{\circ} \mathrm{C}$ and $45^{\circ} \mathrm{C}$ seem to be preserved in the central nervous system

Psychophysical data show that humans and monkeys discriminate smaller temperature differences on the face at $43^{\circ} \mathrm{C}$ and $47^{\circ} \mathrm{C}$ than at $39^{\circ} \mathrm{C}$ (Bushnell et al., 1983b). Our current data support this finding by showing that humans and monkeys more accurately detect smaller temperature changes on the face at $45^{\circ} \mathrm{C}$ than at $39^{\circ} \mathrm{C}$ (see I ables I and II). Since the population of warm fibers shows greater sensitivity around $39^{\circ} \mathrm{C}$ than around $45^{\circ} \mathrm{C}$ (Duclaux and Kenshalo, 1980), its activity cannot be responsible for the superior discrimination in the noxious range. Thus, our current finding of greater attentional effects at $45^{\circ} \mathrm{C}$ than at $39^{\circ} \mathrm{C}$ suggests that attentional factors modulate nociceptive thermal pathways more than innocuous thermal pathways.
Nature of the attentional modulation. We propose that the observed effect of attention on discriminative ability is a selective phenomenon originating in the central nervous system and affecting nociceptive pathways. Although attention can involve intensive factors such as arousal, these factors do not appear to be responsible for the present findings. The human subjects received both incorrect and correct signaled trials. If they were only aroused by the presence of the signal, the latencies would have been shorter in both of these conditions as compared to the unsignaled condition. This was not the case, since the correct signal led to shorter latencies and fewer detection failures and the incorrect signal led to longer latencies and more detection failures. The monkeys received no incorrect signaled condition but instead received a signaled visual condition, in which they were required to withhold a response to the temperature shift. Since the monkeys were required to discriminate the signals in order to perform the task correctly, it is unlikely that the signal served only as an arousing event. The finding that responses to temperature changes around $45^{\circ} \mathrm{C}$ and $39^{\circ} \mathrm{C}$ were differentially affected by the signal lights also suggests that the altentional elfects were a selective rather than a general arousal phenomenon.

Changes in peripheral sensory receptor conditions concomitant to attentional shifts can produce changes in sensation. For example, subjects fixate better to light flashes when instructed to direct attention to them (Oswald, 1959). In the present study, subjects could have made small lip movements in an attempt to better detect the temperature change. However, EMG data showed that monkeys exhibited very little lip movement during the task, and there were no systematic differences in EMG activity between the signaled and unsignaled conditions. Consequently, the observed attentional differences were probably mediated in the central nervous system and not at the peripheral sensory receptors.

We suggest that the attentional effects are not the result of changes in the subjects' decision criterion but are the result of changes in sensory neural pathways. If subjects shifted their decision criterion on signaled trials so that they were more willing to respond to a perceived change in sensation, they should have an increased tendency to respond in the absence of a true temperature change, i.e., early release. However, neither the humans nor the monkeys produced more early releases on noxious signaled trials than on noxious unsignaled trials. The early releases in the current paradigm are similar to "false alarms" in forced choice paradigms designed for signal detection analysis (Green and Swets, 1966). However, since the current study did not utilize a forced choice paradigm nor include trials without a signal, the data cannot be analyzed using a standard signal detection theory analysis.

The attentional effects are not the result of differences in motor preparation, since the identical motor response was required in all conditions. Finally, the fact that the attentional manipulations affected detection of temperature changes at $45^{\circ} \mathrm{C}$ differently than changes at $39^{\circ} \mathrm{C}$ suggests that these effects are specific to certain sensory pathways. These findings suggest that attention may affect the actual perception of a stimulus as well as the reaction to that stimulus.

Effects of attention in other modalities. Posner $(1978,1980)$ and Posner et al. $(1978,1980)$ have shown that attentional manipulations similar to those used in the present study affect human response latencies to visual stimuli. As in our study, a correct signal facilitated stimulus detection and an incorrect signal encumbered stimulus detection. Such manipulations have reliably produced effects in the visual modality but not as reliably in the tactile and auditory modalities (Klein and Posner, 1974; Posner et al., 1978; Posner, 1978). Posner (1978) proposed that attentional manipulations may only affect detection of stimuli that do not contain an alerting quality. If it is assumed that a noxious heat stimulus has more of an alerting quality than an innocuous warm stimulus, then our data do not substantiate this hypothesis. Instead, attention may most effectively modify activity in sensory systems of greatest importance to the organism. Since primates are visually oriented animals, attention may allow them to 
more effectively extract important visual cues from the environment. Similarly, the ability to filter out near-threshold painful stimuli is important to an animal that encounters many mildly painful stimuli in his daily experience. Experimental mlar nipulations that alter the motivational aspects of a stimulus could also influence attentional modulation. For example, if the incentive value of the innocuous warming stimulus was increased, one might find greater attentional effects on such stimuli.

The facl that attentional manipulations can affect stimulus detection in various modalities shows that the modulatory effects we observed are not limited to nociceptive pathways. The neural substrate of selective attention in nociceptive pathways is not known. Neurophysiological studies in the visual system indicate that spatially selective visual attention influences higher-order cortical neurons (area 7) but not neurons involved in earlier stages of sensory processing (Wurtz and Mohler, 1976; Robinson et al., 1978; Wurtz et al., 1980; Bushnell et al., 1981). Although several descending modulatory systems modify nociceptive pathways at early stages of sensory processing (Mayer and Price, 1976; Basbaum and Fields, 1978; Dubner and Bennett, 1983), selective attention in nociceptive pathways may also involve modulatory systems active at thalamic and cortical sites.

\section{References}

Ahles, T. A., E. B. Blanchard, and H. Leventhal (1983) Cognitive control of pain: Attention to the sensory aspects of the cold pressor stimulus. Cognitive Therapy Res. 7: 159-177.

Basbaum, A. I., and H. L. Fields (1978) Endogenous pain control mechanisms: Review and hypothesis. Ann. Neurol. 4: 451-462.

Beitel, R. E., and R. Dubner (1976) Responses of unmyelinated (C) polymodal nociceptors to thermal stimuli applied to the monkey's face. J. Neurophysiol. 39: 1160-1175.

Berlyne, D. E. (1969) The development of the concept of attention in psychology. In Attention in Neurophysiology: An International Conference, C. R. Evans and T. B. Mulholland, eds., pp. 27-39, Butterworths, London.

Bushnell, M. C., M. E. Goldberg, and D. L. Robinson (1981) Behavioral enhancement of visual responses in monkey cerebral cortex. I. Modulation in posterior parietal cortex related to selective visual attention. J. Neurophysiol. 46: 755-772.

Bushnell, M. C., R. L. Jones, G. H. Duncan, and R. Dubner (1983a) Effects of attention on detection of noxious and innocuous thermal stimuli. Soc. Neurosci. Abstr. 9: 473.

Bushnell, M. C. M. B. Taylor, G. H. Duncan, and R. Dubner (1983b) Discrimination of innocuous and noxious thermal stimuli applied to the face in human and monkey. Somatosensory Res. 1: 119-129.

Bushnell, M. C., G. H. Duncan, R. Dubner, and L. F. He (1984) Activity of trigeminothalamic neurons in medullary dorsal horn of awake monkeys trained in a thermal discrimination task. J. Neurophysiol. 52; 170-187.

Casey, K. L., and T. J. Morrow (1983) Nocifensive responses to cutaneous thermal stimuli in the cat: Stimulus-response profiles, latencies, and afferent activity. J. Neurophysiol. 50: 1497-1515.

Craig, K. D., H. Best, and J. A. Best (1978) Self-regulatory effects of monitoring sensory and affective dimensions of pain. J. Consulting Clin. Psychol. 46: 573-574.

Duclaux, R. and D. R. Kenshalo, Sr. (1980) Response characteristics of cutaneous warm receptors in the monkey. J. Neurophysiol. 43: 1-15.

Dubner, R. and G. J. Bennett (1983) Spinal and trigeminal mechanisms of nociception. Annu. Rev. Neurosci. 6: 381-418.

Dubner, R., and J. W. Hu (1977) Myelinated (A-delta) nociceptive afferents innervating the monkey's face. J. Dent. Res. 56: A167.

Dubner, R., D. D. Price, R. E. Beitel, and J. W. Hu (1977) Peripheral neural correlates of behavior in monkey and human related to sensory-discriminative aspects of pain. In Pain in the Trigeminal Region, D. J. Anderson and B. Matthews, eds., pp. 57-66, Elsevier-North Holland Publishing Co., Amsterdam.

Gracely, R. H., P. McGrath, and R. Dubner (1978) Ratio scales of sensory and affective pain descriptors. Pain 5: 5-18.
Green, D. M. and J. A. Swets (1966) Signal Detection Theory and Psychophysics, John Wiley \& Sons, New York.

Hayes, R. L., R. Dubner, and D. S. Hoffman (1981) Neuronal activity in medullary dorsal horn of awake monkeys trained in a thermal discrimination task. II. Behavioral modulation of responses to thermal and mechanical stimuli. J. Neurophysiol. 46: 428-443.

Hoffman, D. S., R. Dubner, R. L. Hayes, and T. P. Medlin (1981) Neuronal activity in medullary dorsal horn of awake monkeys trained in a thermal discrimination task. I. Responses to innocuous and noxious thermal stimuli. J. Neurophysiol. 46: 409-427.

Hyvärinen, J., A. Poranen, and Y. Jokinen (1980) Influence of attentive behavior on neuronal responses to vibration in primary somatosensory cortex of the monkey. J. Neurophysiol. 43: 870-882.

Klein, R. M., and M. I. Posner (1974) Attention to visual and kinesthetic components of skills. Brain Res. 71: 401-411.

Leventhal, H., D. Brown, S. Shacham, and G. Engquist (1979) Effects of preparatory information about sensations, threat of pain, and attention on cold pressor distress. J. Personality Social Psychol. 37: 688-714.

Levine, J. D., N. C. Gordon, R. Smith, and H. L. Fields (1982) Postoperative pain: Effect of extent of injury and attention. Brain Res. 234: 500-504.

Mayer, D. J., and D. D. Price (1976) Central nervous system mechanisms of analgesia. Pain 2: 379-404.

McCaul, K. D., and C. Haugtvedt (1982) Attention, distraction, and coldpressor pain. J. Personality Social Psychol. 43: 154-162.

Melzack, R., and K. L. Casey (1968) Sensory, motivational and central control determinants of pain. In The Skin Senses, D. R. Kenshalo, ed., pp. 423443, Charles C Thomas, Springfield, IL.

Melzack, R., and P. D. Wall (1965) Pain mechanisms: A new theory. Science 150: $971-979$.

Näätänen, R. (1975) Selective attention and evoked potentials in humans: A critical review. Biol. Psychol. 2: 237-307.

Oswald. I. (1959) The human alpha rhythm and visual alertness. Electroencephalography Clin. Neurophysiol. 11: 601-602, 1959.

Posner, M. I. (1978) Chronometric Explorations of Mind, L. Erlbaum Ass. Hillsdale, New Jersey.

Posner, M. I. (1980) Orienting of attention. Quart. J. Exp. Psychol. 32: 3-25.

Posner, M. I. M. J. Nissen, and W. C. Ogden (1978) Attended and unattended processing modes: The role of set for spatial location. In Modes of Perceiving and Processing Information, H. L. Pick and I. J. Saltzman, eds., pp. 137-157, L. Erlbaum Ass., Hillsdale, New Jersey.

Posner, M. I., C. R. R. Snyder, and B. J. Davidson (1980) Attention and the detection of signals. J. Exp. Psychol. Gen. 109: 160-174.

Poulcs, D. A., and J. T. Molt (1976) Response of central trigeminal neurons to cutaneous thermal stimulation. In Sensory Functions of the Skin in Primates, Y. Zotterman, ed., pp. 263-283, Pergamon, Oxford.

Price, D. D., and R. Dubner (1977) Neurons that subserve the sensorydiscriminative aspects of pain. Pain 3: 307-338.

Price, D. D., R. Dubner, J. W. Hu (1976) Trigeminothalamic neurons in nucleus caudalis responsive to tactile, thermal, and nociceptive stimulation of the monkey's face. J. Neurophysiol. 39: 936-953.

Robinson, D. L., M. E. Goldberg, and G. B. Stanton (1978) Parietal association cortex in the primate: Sensory mechanisms and behavioral modulation. J. Neurophysiol. 41: 910-932.

Sumino, R., and R. Dubner (1981) Response characteristics of specific thermoreceptive afferents innervating monkey facial skin and their relationship to human thermal sensitivity. Brain Res. Rev. 3: 105-122.

Sumino, R., R. Dubner, and S. Starkman (1973) Responses of small myelinated "warm" fibers to noxious heat stimuli applied to the monkey's face. Brain Res. 62: 260-263.

Thelin, M. H., and R. A. Fry (1981) The effect of modeling and selective attention on pain tolerance. J. Behav. Ther. Exp. Psychol. 12: 225-229.

Willer, J. C., F. Boureau, and D. Albe-Fessard (1979) Supraspinal influences on nociceptive flexion reflex and pain sensation in man. Brain Res. 179: 61-68.

Wurtz, R. H., and C. W. Mohler (1976) Organization of monkey superior colliculus: Enhanced visual response of superficial layer cells. J. Neurophysiol. 39: 745-765.

Wurtz, R. H., M. E. Goldberg, and D. L. Robinson (1980) Behavioral modulation of visual responses in the monkey: Stimulus selection for attention and movement. Prog. Psychobiol. Physiol. Psychol. 9: 43-83. 